
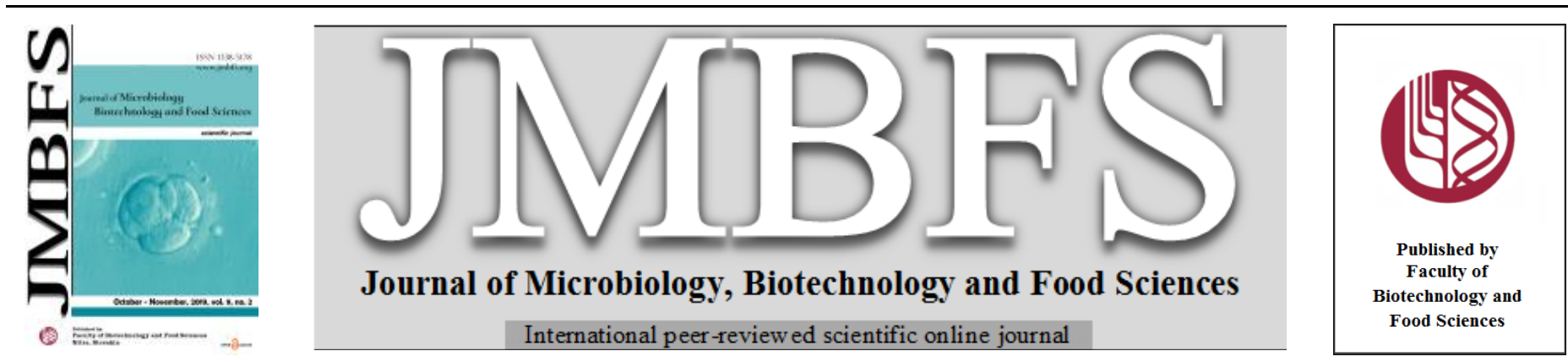

\title{
DELIBERATING PLANT GROWTH PROMOTING AND MINERAL-WEATHERING PROFICIENCY OF STREPTOMYCES NANHAIENSIS STRAIN YM4 FOR NUTRITIONAL BENEFIT OF MILLET CROP (PENNISETUM GLAUCUM)
}

\section{Keyur B. Patel, Janki N. Thakker*}

Address(es):

Department of Biotechnology, P.D. Patel Institute of Applied Sciences, Charotar University of Science and Technology, CHARUSAT Campus, Changa-388421, Anand (Gujarat), India : +91-2697-247500/248133*2194.

*Corresponding author: jankithakker.bt@ charusat.ac.in

doi: 10.15414/jmbfs.2020.9.4.721-726

\section{ARTICLE INFO}

Received 27. 11. 2018

Revised 29. 8. 2019

Accepted 2. 9. 2019

Published 3. 2. 2020

Regular article

open $\partial_{\text {ACCESS }}$

\begin{abstract}
Plants require essential elements like $\mathrm{C}, \mathrm{H}, \mathrm{O}, \mathrm{N}, \mathrm{P}, \mathrm{K}$, considered as a macro elements and $\mathrm{Zn}$ as a micro element. This elemental approach can be done either by naturally or organic/inorganic fertilizers, conventionally. Considering the sustainable approach towards plant growth and development, usage of organic and inorganic fertilizers reduced by using biofertilizer with mineral weathering efficiency. Such a strain belong to family Actinomycetes, Streptomyces nanhaiensis strain YM4 was isolated from rhizosphere of rajagra plant of Khambhat region helps to plant growth promotion and mineral solubilisation efficiency. Present report suggest that it produces $73 \mu \mathrm{g} \mathrm{ml}^{-1}$ of indolic compounds and $4.48 \mu \mathrm{mol} \mathrm{ml}^{-1}$ ammonia production. Along with that it has an efficiency to solubilize $232 \mathrm{mg} \mathrm{ml}^{-1}$ of phosphate, $41.6 \mathrm{mg} \mathrm{ml}^{-1}$ of potassium and $41.16 \mathrm{ppm}$ of zinc in laboratory conditions. The pot trial of liquid bioformulation of strain YM4 on millet crop enhance the plant growth with enhanced leaf biomass and pigment production, significantly. Effect of strain helps to mineralize and accumulate minerals in rhizospheric region of the millet crop.
\end{abstract}

\section{INTRODUCTION}

Global Hunger Index (GHI) scores 2017 reports that; the level of hunger in the world has decreased by 27 present from the year 2000 . Out of the 119 countries assessed, one falls in the extremely alarming range on the GHI Severity Scale; 7 fall in the alarming range; 44 in the serious range; and 24 in the moderate range. Data underlying the calculation of the Global Hunger Index score, 2017 represents that India ranked $100^{\text {th }}$ position in serious range and has $14.5 \%$ population in undernourished condition (www.globalhungerindex.org/). The term nutritional quality of food means amounts of the essential nutrients (protein, fat, carbohydrate, minerals and vitamins) which was present in the food to maintain overall physical health and these content is initially affected by soil and growing conditions, storage and finally processing (http://www.reference.md/files/D009/mD009753.html). Therefore, considering dietary quality of food is one of the approach to overwhelm the problem of malnutrition.

Plants require essential elements for their growth and development like other living organisms. Except of carbon, hydrogen and oxygen, other 13 elements (nitrogen, phosphorous, potassium, calcium, magnesium, sulphur, iron, zinc, manganese, copper, boron, molybdenum and chlorine) are supplied either from soil minerals, organic matters and by organic or inorganic fertilizers (Silva $\&$ Uchida, 2000). Nitrogen is classified as the major essential element which is biologically combined with $\mathrm{C}, \mathrm{H}, \mathrm{O}$ and $\mathrm{S}$ to form several amino acids, which is a core of any protein structure. Another major nutrient element next to nitrogen in augmenting plant metabolic activity which ultimately reflects on the crop yields is phosphorus, meaning it is required relatively in large amounts for plant growth and production. Being a constituent of nucleic acids, phytins, phospholipids, ATP, etc., it is involved in energy transfer, photosynthesis, transformation of carbohydrates, nutrient movement within the plant and transfer of genetic characteristics from one generation to the next. Phosphorus taken up in different forms by the cell, but majorly absorbed in the form of hydrogen phosphate ion $\left(\mathrm{HPO}_{4}{ }^{2-}\right)$ or dihydrogen phosphate ion $\left(\mathrm{H}_{2} \mathrm{PO}^{4}\right)$ (Sultenfuss \& Doyle, 1999) Potassium $(\mathrm{K})$ is the third most important essential nutrient for plant growth after phosphorus. Three forms of $\mathrm{K}$ (unavailable, slowly available or fixed and readily available or exchangeable) exist in soil (Sindhu, Parmar, \& Phour, 2014). As large amounts are absorbed from the root zone in the production of most agronomic crops. The total $\mathrm{K}$ content of soils frequently exceeds $20,000 \mathrm{ppm}$ (parts per million). Unlike nitrogen and phosphorus, potassium does not participate in any vital compound formation but it assists in several process like stomatal regulation and photosynthesis by balancing electrical charges, sugar translocation for growth and storage (Silva \& Uchida, 2000). The essential micronutrient zinc occurs in plants either as a free ion, or as a complex with a variety of low molecular weight compounds (Brown, Cakmak, \& Zhang, 1993). Zinc may also be incorporated as a component of proteins and other macromolecules.

Staple crops (i.e. plants that constitute the major food item in the diets of people in developing countries) unfortunately contain low levels of micronutrients, making them insufficient to meet the minimum daily requirements. It has been reported that millet is a very good source of energy and basically coarse grain crop originated from India and Africa. Millet crop is a C4 plant with higher photosynthetic efficiency and tolerance towards temperature and drought Therefore this cereal is cultivated and used as a major cereal crop species for the people living Indian subcontinent and Africa (Medici et al., 2018). In case of nutritional approach, millet crop was found significant rich in starch, soluble and insoluble dietary fibres, minerals and antioxidants (Ragaee, Abdel-Aal, \& Noaman, 2006) and rich source of phytochemicals and micronutrients (Medici et al., 2018). Nutrient deficiency in population can be overcome by mineral uptake through such organisms which can mineralize and accumulate minerals in the vicinity of rhizosphere. Considering the sustainable approach towards plant growth and development, usage of organic and inorganic fertilizers reduced by using biofertilizer with mineral solubilizing efficiency. Biofertilizers - "an invisible engineers of soil fertility and the central core of biogeochemical cycles performed besides their habitat in rhizosphere or bulk soil" (Gadd, 2010) and produce phytohormones along with enhance nutrient uptake by mineral solubilisation.

Plant growth promoting bacteria influence plant growth through phytohormone (IAA) production, ammonia production, phosphorus, potassium, zinc and iron solubilization which are of great importance (Bhattacharyya \& Jha, 2012) Number of plant growth promoting bacteria such as Bacillus, Providencia, Brevundimonas, Ochrobacterium, Azotobacter, Anabaena (Dhuldhaj and Pandya 2017; Khalid et al., 2015; Sharma et al., 2012) involve in enhancing the mineral density of cereal crops and few reports on Actinobacteria for improvement chickpea seed mineral density (Sathya et al., 2016). In this study, Strptomyces nanhaensis strain YM4 isolated from coastal agricultural land of 
Khmabhat, Gujarat, India was tested for the PGP effects and minera solubilisation (phosphorus, potassium and zinc) and tested on Millet crop under pot trials.

\section{MATERIALS AND METHODS}

\section{Sample collection, isolation and identification of Actinobacteria}

Rhizospheric soil of Rajagra plant (Amaranths Sp.) was collected from coasta agricultural land of Khambhat, Gujarat, India $\left(22^{\circ} 17^{\prime} 33.5^{\prime \prime} \mathrm{N}, 72^{\circ} 40^{\prime} 15.6 " \mathrm{E}\right)$. The soil loosely adhere to plant roots was removed and sample was oven dried for overnight. Next day, $0.5 \mathrm{gm}$ of soil sample was suspended in sterile distilled water followed by serial dilution in the ratio of 1:9 (v/v) and vortexed overnight at room temperature. Serially diluted suspension was inoculated on Yeast extract Mannitol agar supplemented with $1 \% \mathrm{NaCl}$ using spread plate technique and incubated at $37 \pm 2^{\circ} \mathrm{C}$ for 13 to 15 days (Goswami et al., 2014). After incubation period, morphologically distinct colonies were sub-cultured to obtained isolated pure colonies.

The isolate was inoculated on Nutrient agar plates and incubated at $37^{\circ} \mathrm{C} \pm 2^{\circ} \mathrm{C}$ for 15 days. Structural morphologies such as size, shape, elevation, surface, margin, aerial and substrate mycelium color, pigment production were analysed (Agrawal \& Kotasthane, 2012; Rajawat, Singh, \& Saxena, 2014; Saif, Khan, Zaidi, \& Ahmad, 2014). Molecular identification was done based on 16S rRNA gene sequencing. Universal forward (FP): 5'-AGAGTTTGATCCTGGCTCAG3' and Reverse Primer (RP): 5'-AAGGAGGTGATCCAGCCGCA-3' were used to amplify $16 \mathrm{~S}$ rRNA gene sequence by means of polymerase chain reaction. Primers were procured from 1st BASE (Agile Life Science Technologies India Pvt. Ltd.) and amplified gene product was sequenced at 1st BASE (Agile Life Science Technologies India Pvt. Ltd.). Gene sequence homology was done by using online sequence alignment search program BLASTn which is available at NCBI web portal (Altschul et al., 1990). Further alignment of gene sequence was done with ClustalX and phylogenetic Neighbor-Joining tree was constructed with bootstrap value of 1000 using MEGA 4.0 software (Tamura et al., 2007). Gene sequence of YM4 strain was submitted under GenBank nucleotide sequence database. Further identification was completed by the biochemical evaluations portrayed and scrutinized with reports mentioned by Tian et al. (2012).

\section{Quantitative estimation of Indole Acetic Acid (IAA) production}

Spectrophotometric estimation of IAA was performed as per the method developed by Bric et al. (1991) with modifications adapted by Goswami et al (2014). Spore suspension culture of the bacterial strain YM4 grown in nutrien broth (NB) medium supplemented with varying concentrations L- tryptophan $\left(200,400,600,800,1000 \mu \mathrm{g} \cdot \mathrm{ml}^{-1}\right)$ at $37 \pm 2{ }^{\circ} \mathrm{C}$ was mixed with Salkowski reagen $\left(50 \mathrm{ml}, 35 \%\right.$ of perchloric acid, $1 \mathrm{ml} 0.5 \mathrm{M} \mathrm{FeCl}_{3}$ solution) in the ratio of $1: 1(\mathrm{v} / \mathrm{v})$ Development of pink colour indicates production of indolic compounds and its optical density was recorded at $530 \mathrm{~nm}$. Concentration of IAA produced was estimated against standard curve of IAA in the range of $10-100 \mu \mathrm{g} \cdot \mathrm{ml}^{-1}$.

\section{Quantitative estimation of Ammonia Production}

Ammonia production was estimated by using Nesslerization reaction as mentioned by (Cappuccino \& Sherman, 2005). Bacterial isolates were grown in peptone water broth for thirteen days at $37 \pm 2^{\circ} \mathrm{C}$. Culture supernatant $(0.2 \mathrm{ml})$ was mixed with $(1 \mathrm{ml})$ Nessler's reagent and volume of this mixture was made up to $8.5 \mathrm{ml}$ by addition of ammonia free distilled water. Development of brown or reddish brown from yellow color is the indication of ammonia produced, and its optical density was measured at $450 \mathrm{~nm}$ using spectrophotometer. The concentration of ammonia was estimated using the standard curve of ammonium sulphate in the range of $0.1-1 \mu \mathrm{mol} \mathrm{m}^{-1}$

\section{Estimation of phosphate solubilisation}

The method developed by Pikovskaya (1948) was used for quantitative estimation of tri calcium phosphate solubilisation with slight modification. Quanlitative estimation was performed by solid Pikovskaya agar plate supplemented with tri calcium phosphate as a source of phosphate. The solubilization of the phosphate was observed after 10 days of incubation period at $37^{\circ} \mathrm{C}$ as a zone of clearance with a measured diameter (Saif et al., 2014) Solubilization index was measured by using formula:

$$
\text { solubilization index }=\frac{\text { Zone diameter }}{\text { Colony diameter }} \times 100
$$

Qualitative analysis of phosphate solubilization ability of test isolate was determined in presence of different sugars such as glucose, fructose, sucrose and mannitol in the modified Pikovskaya's medium. The amount of soluble phosphate was assessed from the cell free culture supernatant with stannous chloride method as described by King (1932).

\section{Assessment of potassium solubilisation}

Sample culture was spot inoculated on Alaksandrov agar medium plate $(\mathrm{pH}$ $7.2 \pm 0.2$ ) containing 5.0 g. $\mathrm{L}^{-1}$ glucose, 0.5 g. $\mathrm{L}^{-1}$ magnesium sulphate, 0.005 g.L $\mathrm{L}^{-1}$ ferric chloride, 0.1 g.L. ${ }^{-1}$ calcium carbonate, 2 g.L $\mathrm{L}^{-1}$ calcium phosphate, and $2 \mathrm{~g}$ $\mathrm{L}^{-1} \mathrm{~K}$-bearing minerals (Potassium alluminosilicate) (Rajawat et al., 2016) with an addition of $2.5 \mathrm{ml}$ Bromothymol blue $(0.5 \%)$ as a $\mathrm{pH}$ indicator dye. The solubilization of potassium was observed after 10 days of incubation period at $37^{\circ} \mathrm{C}$ as a zone of clearance with a measured diameter. Qualitative estimation was performed by inoculating culture in Alaksandrov Liquid medium and incubated at $37^{\circ} \mathrm{C}$. After Incubation time interval ( 0 day, $3^{\text {rd }}$ day, $5^{\text {th }}$ day, $7^{\text {th }}$ day, $9^{\text {th }}$ day and $11^{\text {th }}$ day), medium was centrifuged and supernatant was used for assessment of potassium by sodium cobaltinitrite method using spectrophotometer at $623 \mathrm{~nm}$ (Vikram et al., 2014).

\section{Assessment of zinc Solubilization}

Minimal salt medium embedded with Glucose $(2 \%)$ as a carbon source and Zinc Oxide $(0.1 \%)$ (Saravanan et al., 2007) as a metal compound was used. Culture suspension was spot inoculated on agar plates and $6 \times 10^{8}$ spores $\mathrm{ml}^{-1}$ was inoculated in broth and incubated at $37^{\circ} \mathrm{C}$ for 10 days. After inoculation, agar plate was observed for zone of clearance and culture supernatant after centrifugation step, send for atomic absorption spectroscopy (AAS) at Gujarat laboratory, Ahmedabad.

\section{Pot trials}

The Pot trial conditions used were as follows. The experiment was carried out in the year 2017 October month (post-rainy cropping season) at CHARUSAT campus, Anand, Gujarat, India. Soil was treated with farm yard manure (FYM) with ratio 15:5 (w/w) and kept for a week for proper decomposition. The mineral content of the soil includes $25.7 \mathrm{~kg} \mathrm{ha}^{-1}$ soil of available phosphorous, $196 \mathrm{~kg} \mathrm{ha}^{-1}$ soil of available potassium and $0.43 \mathrm{ppm}$ of available $\mathrm{Zn}$. The soil was kept unseeded and filled 400 grams of soil in each pots $\left(15 \mathrm{~cm}^{*} 10 \mathrm{~cm}\right)$. An analysis was set up for the development of millet plant under the normal soil condition with negative control. Seeds were surface sterilized and mixed with liquid formulation and sown in each pot. Following 30 days of germination, each plantlets were uprooted and tested for vegetative parameter such as root length, shoot length, total length, number of leaf, leaf area index, leaf length, dry biomass, turgid biomass, leaf relative water content, etc (Goswami et al., 2014). Soil sample was sent for elemental analysis after uprooting the plants to check mineral solubilisation using AAS at Gujarat Laboratory, Ahmedabad, Gujarat.

\section{Statistical analysis}

Significant difference of each vegetative parameter of treated and non-treated plantlets for control conditions were analysed by Analysis of variance (ANOVASingle factor) using triplicate values. Mean values were compared at significance levels of $5 \%, 1 \%$ and $0.1 \%$ least significant difference (LSD).

\section{RESULTS AND DISCUSSION}

\section{Isolation and Identification of Actinobacteria}

A rhizosheric soil of Rajagra plant, from which strain YM4 was first isolated on yeast extract mannitol agar plate and sub-cultured several times on the nutrient agar plate to obtain pure isolated colony. Strain YM4 produced white coloured colonies with chalky aerial hyphae while yellowish to light brownish submerged hyphae on aging (Figure 1). Nutrient composition greatly influence the growth and morphology of the organism. Strain YM4 unable to produce an aerial hyphae on the Potato agar plate and produced slightly raised regular colonies with even margin (Table 1).

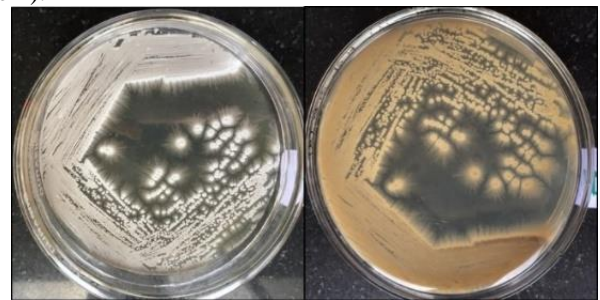

Figure 1 Morphology of strain YM4 cultivated on nutrient agar plate after 15 days of incubation (A) Aerial view; (B) Rear view. 
Table 1 Morphological and biochemical characterization of Strain YM4 isolated from rhizospheric soil of Khambhat.

\begin{tabular}{lc}
\hline Parameters & Result \\
\hline Morphological characterization & \\
\hline Size & Small \\
Shape & Round \\
Texture & Powdery \\
Elevation & Raised \\
Opacity & Opaque \\
Pigmentation & Chalky Pigment \\
Aerial Mycelial Color & White \\
Submerged Mycelial Color & Yellowish to Brownish \\
\hline Biochemical characterization & \\
\hline Sugar Utilization test & \\
(Xylose, Dextrose, Galactose, Melibiose, L- & \\
Arabinose, Mannose, ONPG) & + \\
(Trehalose, Lactose, Mannose, Fructose, Sucrose, & \\
Cellobiose, Xylitol, D-Arabinose, Maltose, & \\
Glycerol, Sorbose, Dulcitol) & - \\
Methyl Red Test & \\
Vogus Proskauer Test & - \\
Nitrate reduction & \\
TSI test & + \\
Urea Hydrolysis & - \\
Starch Hydrolysis & - \\
Cimmon Citrate agar test & \\
Gelatin Hydrolysis & - \\
H2S Production & + \\
\hline
\end{tabular}

Biochemical analysis of strain YM4 showed that it is gram positive, VogusProskauer (VP) test and citrate utilization test Positive, VP test determines acetylmethyl carbinol production by organism from glucose fermentation. In alkaline condition and presence of oxygen, this acetylmethyl carbinol converted into diacetyl to form a pinkish red polymer. While, citrate utilization test determines the ability of bacteria to use citrate as a sole source of carbon and energy. This ability depends upon the presence of citrate permease that facilitates transport of citrate into bacterium. Once inside the bacterium, it initiates Kreb's cycle and thus plays important role in photosynthetic mechanisms of plants. While Methyl red (MR) test, Urea hydrolysis, gelatinase test, nitrate reduction test, $\mathrm{H}_{2} \mathrm{~S}$ production test showed negative result. Moreover, several soil enzymetic test such as, amylase production, lipase test, protease test, glucanase test and chitinase test showed clear colorless and/or halo zone in the vicinity of the colony. Tian et al. (2012) mentioned the novel strain of actinobacteria isolated from deep-sea sediments was positive for starch and tween-20 hydrolysis, nitrate reduction, catalase and weakly positive for hydrolysis of cellulose but negative for gelatin and Tween 80 hydrolysis, $\mathrm{H}_{2} \mathrm{~S}$ production, urea and oxidase activity.

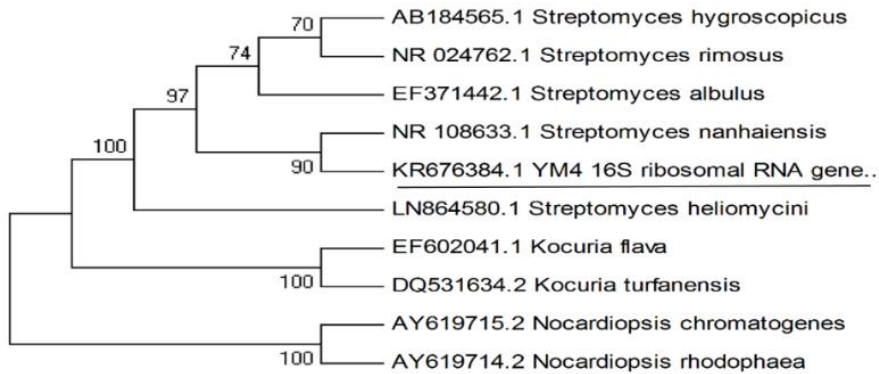

Figure 2 phylogenetic Neighbor joining tree analysis based on the 16S rRNA gene sequence showing the relationship between strain YM4 and related members of Streptomyces species and out group members of other Actinobacterial species. Analysis involved ten nucleotide gene sequences and the evolutionary analyses were conducted in MEGA 4.

The 16S rRNA amplified gene sequence were aligned to database at NCBI web portal and sequence seems similar with the Actiobacteria bacterium, which is submitted to GenBank with accession number KR676384.1. Further biochemical assessment and phylogenetic tree analysis (Figure 2) confirm the similarity with Streptomyces nanhaiensis (NR 108633.1) strain SCSIO 01248 which was isolated from marine sediments by Tian et al. (2012).

\section{Quantitative analysis of Indole acetic acid (IAA) production}

IAA production is an influential trait possessed by PGPR as this phytohormone enables plant to develop highly organised root system by which uptake of nutrients becomes more efficient (Tsavkelova et al., 2007). Produced indole in bacteria serves stability to plasmid, spore formation and drug resistance (Lee $\boldsymbol{\&}$ Lee, 2010). IAA production by the strain YM4 is following tryptophan dependent pathway. L-tryptophan is generally considered as precursor molecule for Indolic compounds because of its addition enhances the production of IAA by bacterial cultures. When additional L-tryptophan was supplemented, the organism follows tryptophan dependent pathway to produce an indolic compounds. IAA production is dependent on the presence on L-tryptophan in the medium (Barazani and Friedman 2000) as the organism utilize the precursor Ltryptophan to produce IAA. Quantitative analysis of IAA depicted that strain YM4 could produce the indolic compounds which helps in the plant growth promotion. IAA from the culture supernatant was determined at 3, 5, 7,9 and 11days of incubation. There was an increase in the production of IAA day by day. Maximum production of IAA was found $73 \mu \mathrm{g} \mathrm{ml}{ }^{-1}$ on $9^{\text {th }}$ day of growth in the medium supplemented with $400 \mu \mathrm{g} \mathrm{ml} l^{-1} \mathrm{~L}$-tryptophan (Figure 3). After $9^{\text {th }}$ day of incubation, there was a decrease in the production of IAA and it remains approximately constant till day 11 . Ahmad et al. (2008) reported that increase in conformation i.e., (Indolic conversion) with an increase in L-tryptophan supplemented in the medium. Manulis et al. (1992) have reported that Streptomyces spp. Secrete Indole moieties when fed with tryptophan into the medium. Microbial biosynthesis of IAA in soil enhanced by means of tryptophan from root exudates or cell denaturation. It has been reported that application of organic fertilizers can enhance the tryptophan levels by aerobic or anaerobic microbial transformation in the soil (Arkhipchenko et al., 2006). Treatment of bacterial inoculum into the soil during Millet crop cultivation reflects its effect in the form of length of roots as it contributes in plant growth promotion by root growth promotion.

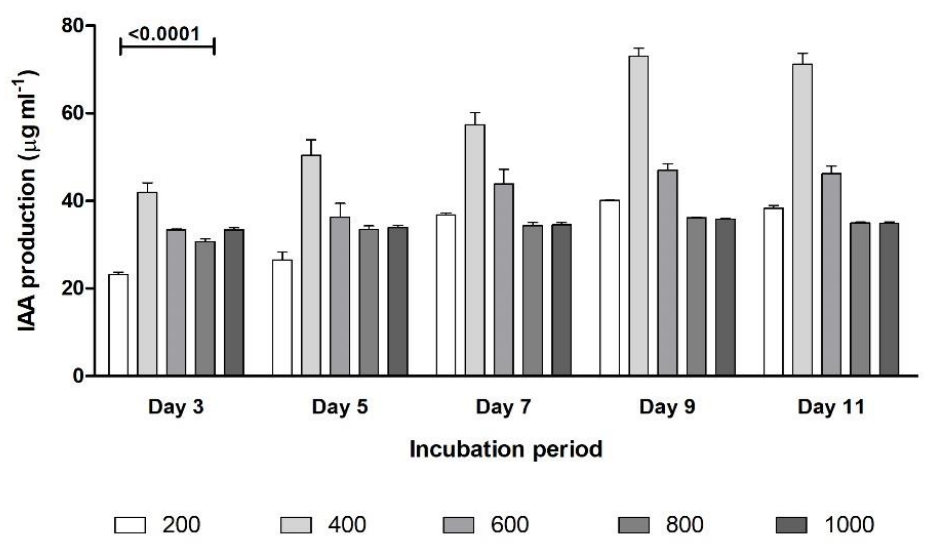

Figure 3 Production of IAA by Streptomyces strain YM4 in nutrient media supplemented with different concentration of L-tryptophan.

\section{Quantitative assessment of Ammonia production}

Out of the 13 essential minerals, macronutrient (nitrogen, phosphorus and potassium) and micronutrient (zinc) attended more consideration in this research because of its important role in plant growth and development. Nitrogen is classified as the major essential element which is biologically combined with $\mathrm{C}$, $\mathrm{H}, \mathrm{O}$ and $\mathrm{S}$ to form several amino acids, which is a core of any protein structure. Strain YM4 produced ammonia in peptone water. It produced $4.48 \mu \mathrm{mol} \mathrm{ml}^{-1}$ ammonia on 11th day of incubation after which it was found to decrease and remain constant (Figure 4). Ammonia production by the organism helps in nitrogen availability to the plant. N2 can be converted not only by symbiosis (e.g., Frankia, Anabaena) but also in free-living forms (e.g., Azotobacter, various Actinomycetes) (Uchida 2000). Frankia is a versatile actinobacteria which can fix the N2 by symbiotically and free-living conditions. Other than this, several other actinobacteria such as Arthrobacter, Agromyces, Corynebacterium, Mycobacterium, Micromonospora, Propionibacteria and Streptomyces exhibited nitrogen fixing ability (Sellstedt \& Richau, 2013). 


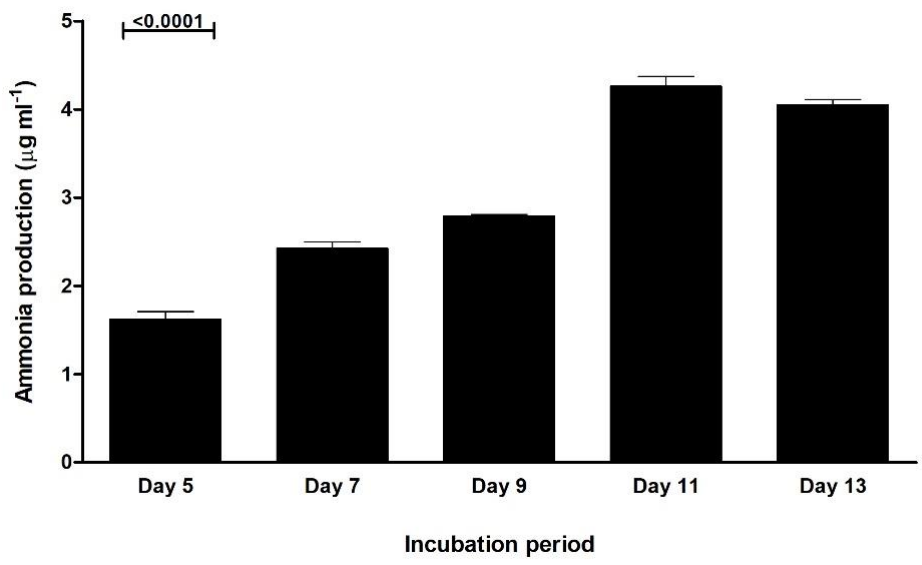

Figure 4 Ammonia production by Streptomyces strain YM4 in peptone water broth.

\section{Qualitative and quantitative assessment of Phosphate mineralization}

Another major nutrient element next to nitrogen is phosphorus and potassium, important in energy transfer and photosynthesis, specifically (Silva \& Uchida, 2000). Phosphorus is an essential element used in number of molecular and biochemical process for energy acquisition, storage and utilization (Weisany $\boldsymbol{e}$ al., 2013). Strain YM4 was tested for its ability to solubilise phosphate. Figure 5 shows clear zone of phosphate solubilisation in the vicinity of the colony as its qualitative test positive. The zone diameter was $18.33 \pm 0.57 \mathrm{~mm}$ whereas; the colony diameter was $4.6 \pm 0.57 \mathrm{~mm}$. The solubilisation index was $392 \pm 66.39$. Quantitative estimation of phosphate solubilisation by strain YM4 showed Maximum $\left(232 \pm 60 \mathrm{mg}^{-1} \mathrm{ml}^{-1}\right)$ on $11^{\text {th }}$ day of incubation period, when supplemented with fructose as a soul carbon source. Phosphate solubilisation is a mineralization of phosphate from soil by acid hydrolysis or phosphatase or phosphohydrolases. In general, phosphate solubilizing bacteria (PSB) excretes organic acids, mainly gluconic acid (Farhat et al., 2015). Sharma et al. (2013) reported that the strains that solubilize Tri-Calcium Phosphate (TCP) in liquid and solid medium could produce organic acids making the $\mathrm{pH}$ of the medium acidic which leads to breakdown of inorganic complex molecule and liberate phosphate ions into the system. Organic acid production by an organism is outcome of carbon source utilization. Carbohydrate metabolism leads to the formation of different organic acid production. In this connection, nature of organic acids liberated into the medium and quantity of particular acid may help in dissolution of phosphate by microorganisms.
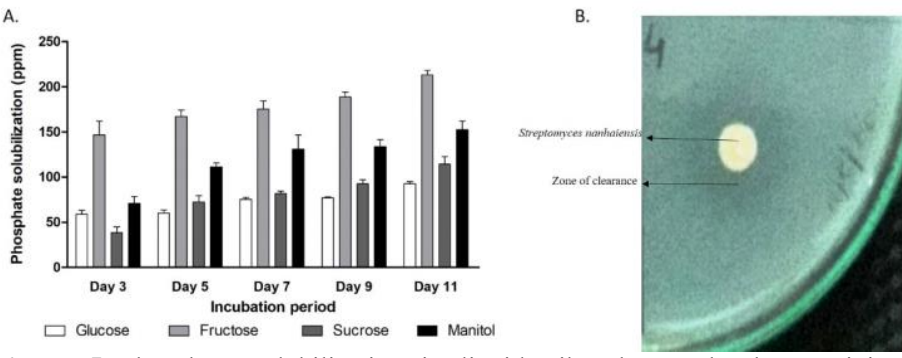

Figure 5 Phosphate solubilization in liquid Pikovskaya's broth containing different sugar as a carbon sources by Streptomyces strain YM4 (A) and Zone of phosphate solubilisation in the vicinity of Streptomyces nanhaiensis strain YM4 on Pikovskaya agar medium (B).

\section{Qualitative and quantitative assessment of Potassium mineralization}

Potassium is a most abundantly absorbed cation plays an important role in enzyme activation, higher plants, photosynthesis activation, suppression of respiration process and maintain cell turgidity, as well. Strain YM4 mineralize $41.6 \mathrm{mg} . \mathrm{ml}^{-1}$ of potassium on $11^{\text {th }}$ day of incubation period. A wide range of bacteria, such as members of the genus Pseudomonas, Burkholderia, Acidithiobacillus ferrooxidans, Bacillus mucilaginosus, Bacillus edaphicus, and B. circulans were found to release potassium from potassium-bearing minerals (Teotia et al., 2017). Liu et al. (2016) has reported about Streptomyces isolated from earthworm's gut and its potential to solubilize potassium from its minerals. Qualitative assessment of potassium showed clear zone $(12.6 \pm 0.75 \mathrm{~mm})$ of potassium solubilisation surrounding the colony diameter $(7.6 \pm 0.5 \mathrm{~mm})$ on Alaksandrov agar plate after 10 days of incubation period. Further estimation on liquid broth medium support the result of quality analysis. Strain YM4 mineralize $41.6 \mathrm{mg} \mathrm{ml}^{-1}$ potassium on $11^{\text {th }}$ day of incubation period (Figure 6), which was estimated spectrophotometrically by sodium cobaltinitrite method.

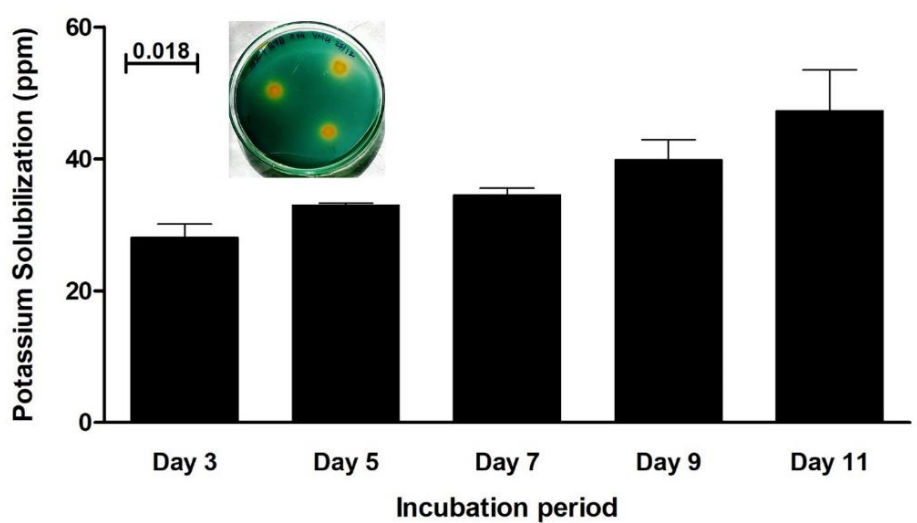

Figure 6 Potassium solubilisation by Streptomyces strain YM4 in liquid Alaksandrov broth containing potassium aluminosilicate as a raw mineral source. The potassium solubilisation potential on the plate showed in inset.

Qualitative and quantitative estimation of Zinc mineralization

Zinc, microelement plays a vital role in various metabolic processes in plants, and its deficiency adversely affects the growth and development of crop plants (Sharma et al., 2012). The result showed that Zinc mineralization by the strain YM4 showed positive on plate agar (Figure 7) with 76.31 solubilisation index. $0.1 \%$ of $\mathrm{ZnO}$ was supplemented in agar plate which was solubilized by strain YM4 which was clearly observed surrounding the colony diameter in the form of zone of clearance. Zinc mineralization was estimated quantitatively in broth supplemented with $0.1 \% \mathrm{ZnO}$ as $\mathrm{Zn}$ source. After incubation of 10 days, culture supernatant was analysed under Atomic absorption spectroscopy (AAS), which indicated that strain has the capacity to solubilize Zinc $41.16 \mathrm{ppm}$.

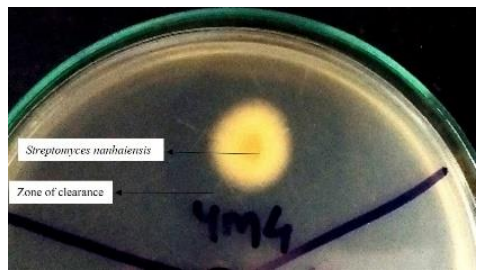

Figure 7 Qualitative analysis of Zinc solubilisation by Streptomyces strain YM4 in Minimal media supplemented with $0.1 \% \mathrm{ZnO}$ as a raw mineral source of $\mathrm{Zn}$.

Pot trials

Millet crop was preferred for the pot trials because of widely accepted as staple crop in semi-arid regions of Asia and Africa. Millet crop is adapted to cultivate in high temperature, low rain fall, low fertility (Rajyalakshmi et al., 2017). Reports of vegetative parameter study of plantlets after 30 days of sowing indicates that strain YM4 helps to improve significant plant length. It helps to increase root length, shoot length and total length of the plant compare to control plant. Prior to utilize by plant system, all these solubilized minerals get accumulated in easily available forms from the soil system. Accumulated soil minerals were analysed by Soil analysis of pot trials at 30 DAS (days after sowing) showed that control soil possess $20 \mathrm{~kg} \mathrm{ha}^{-1}, 150 \mathrm{~kg} \mathrm{ha}^{-1}$ and $0.316 \mathrm{ppm}$ of phosphorus, potassium and zinc. While in case of treated soil showed $15.22 \mathrm{~kg} \mathrm{ha}^{-1}, 163.66 \mathrm{~kg} \mathrm{ha}^{-1}$ and 0.753 ppm of phosphorus, potassium and zinc, respectively (Table 3). Phosphorus content in soil decreases because phosphorus participates from the beginning in core formation, like genetic construction and also participates in photosynthesis and energy transfer. Increased level of potassium and zinc is observed in treated soil because of its role in maturity stage of the plant. Potassium improves crop quality by strengthening straw and helps in grain filling and kernel weight (Sindhu et al., 2014). While increase in level of $\mathrm{Zn}$ in treated soil might be because it is mineralized by an organisms and mobilize as per the requirement of the plant. So, there might be the chances of higher rate of accumulation than the mobilization into the plant and it has structural and functional role and as a cofactor in various metabolic process in plants (Brown et al., 1993). Zinc is also an essential constituent of carbonic anhydrase enzyme which catalyses the reversible hydration of carbon dioxide to bicarbonate and hydrogen ions and has an important in photosynthesis (Ohki, 2000). Bio formulation also promote leaf quality and density which was tested by leaf length, leaf area index, chlorophyll content, total protein content and leaf biomass, as well (Table 2). Chlorophyll a and $\mathrm{b}$ content seems increase but no significant increase in total carotenoid content in treated plant (Figure 8). Ohki (2000) reported that concentration of zinc directly proportional to chlorophyll content. Minor increase in chlorophyll b content in treated plant compare to control plant might be because of zinc mobilization. 
Table 2 Effect of bioformulated Streptomyces strain YM4 on plant vegetative parameters in normal soil in comparison with control of Bajra (Millet crop) after incubation of 30 days after sowing. Values mentioned are mean value of triplicates with standard error of mean.

\begin{tabular}{lcccc}
\hline Vegetative parameters & Control & Treatment & $P$ value & Significance \\
\hline Root length $(\mathbf{c m})$ & $3.83 \pm 0.28$ & $4.7 \pm 0.264$ & 0.018563 & $*$ \\
shoot length $(\mathbf{c m})$ & $4.66 \pm 0.57$ & $6.16 \pm 1.04$ & 0.014173 & $*$ \\
total length $(\mathbf{c m})$ & $23.66 \pm 3.05$ & $34 \pm 1.73$ & 0.007 & $* *$ \\
no of leaves & $4.33 \pm 0.57$ & $4 \pm 0.0$ & 0.373901 & NS \\
leaf length (cm) & $13.66 \pm 2.33$ & $21 \pm 4.7$ & 0.008824 & $* *$ \\
fresh Leaf Weight $(\mathbf{g m})$ & $0.12 \pm 0.02$ & $0.125 \pm 0.123$ & 0.043018 & $*$ \\
Turgid Leaf Weight $(\mathbf{g m})$ & $0.15 \pm 0.001$ & $0.22 \pm 0.002$ & 0.093333 & NS \\
Dry Leaf Weight $(\mathbf{g m})$ & $0.01 \pm 0.003$ & $0.017 \pm 0.007$ & 0.167819 & NS \\
Leaf relative water content & $118.3 \pm 48.08$ & $54.50 \pm 47.03$ & 0.166616 & NS \\
Leaf Area Index (units) & $0.01 \pm 0.002$ & $0.013 \pm 0.005$ & 0.200499 & NS \\
\hline
\end{tabular}

Note: $p$ Value has been calculated using one-way ANOVA and its interpretation is as follows:

Ns ( $p$ Value greater than 0.05$)$ nonsignificant as compared to control.

* ( $p$ Value between 0.05 and 0.01 ) significant at $5 \%$.

** ( $p$ Value between 0.01 and 0.001 ) significant at $1 \%$ as compared to control.

Table 3 Assessment of soil minerals phosphorus, Potassium and Zinc content in control soil and treated soil samples by AAS (Atomic absorption spectroscopy).

\begin{tabular}{cccc}
\hline \multirow{2}{*}{ Treatment } & \multicolumn{3}{c}{ Soil Content } \\
\cline { 2 - 4 } & $\mathbf{P}\left(\mathbf{K g ~ h a}^{-1}\right)$ & $\mathbf{K}\left(\mathbf{K g ~ h a}^{-1}\right)$ & $\mathbf{Z n}(\mathbf{p p m})$ \\
\hline Control & $20.39 \pm 0.33$ & $150.93 \pm 0.83$ & $0.316 \pm 0.015$ \\
YM4 treated & $15.22 \pm 0.25$ & $163.66 \pm 4.04$ & $0.753 \pm 0.025$ \\
P Value & $2.95 \mathrm{E}-05$ & 0.005 & $1.36 \times 10^{-05}$ \\
Significance & $* * *$ & $* *$ & $* * *$ \\
\hline
\end{tabular}

Ns ( $p$ Value greater than 0.05) nonsignificant as compared to control.

* ( $p$ Value between 0.05 and 0.01 ) significant at $5 \%$.

** ( $p$ Value between 0.01 and 0.001 ) significant at $1 \%$ as compared to control.

$* * *$ ( $\mathrm{p}$ Value $<0.001$ ) significant at $0.1 \%$ as compared to control.

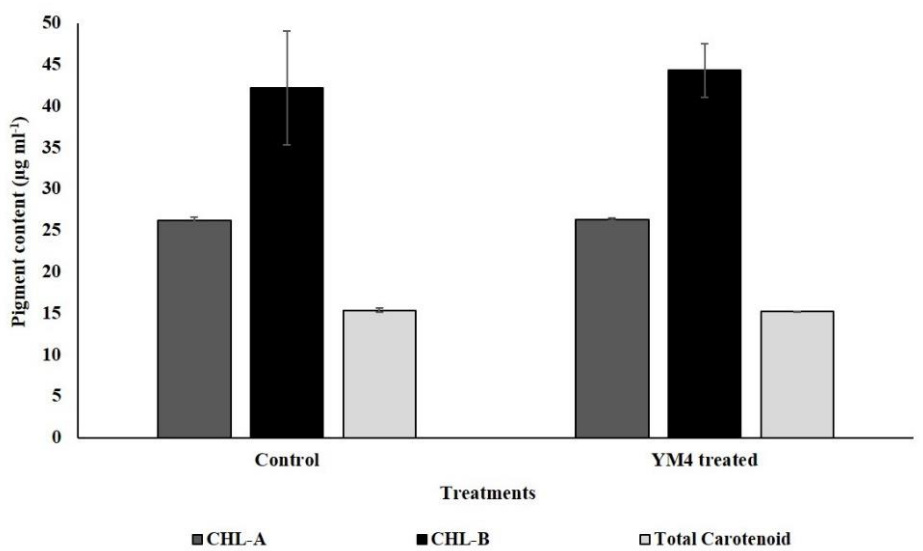

Figure 8 Effect of bioformulated Streptomyces strain YM4 on pigment production of Bajra plant leaf.

\section{CONCLUSION}

Bio-fortification is a three step process in which mineral solubilisation is the initial and very important step towards overwhelming malnutrition. Biofortification of the Millet seeds is promising intervention to overcome malnutrition due to its availability and cost effect, which we successfully incorporated initial step in this study. Further steps such as mineral absorption and its mobilization into the crop is also crucial step for the bio fortification process. This study suggest the further research on mineral mobilization of solubilized minerals and its accumulation to the yield.

\section{REFERENCES}

Agrawal, T., \& Kotasthane, A. S. (2012). Chitinolytic assay of indigenous Trichoderma isolates collected from different geographical locations of Chhattisgarh in Central India. SpringerPlus, 1(1), 73.

https://doi.org/10.1186/2193-1801-1-73
Altschul, S. F., Gish, W., Miller, W., Myers, E. W., \& Lipman, D. J. (1990) Basic local alignment search tool. Journal of molecular biology, 215(3), 403-410. https://doi.org/10.1016/s0022-2836(05)80360-2

Arkhipchenko, I. A., Shaposhnikov, A. I., \& Kravchenko, L. V. (2006). Tryptophan concentration of animal wastes and organic fertilizers. Applied soil ecology, 34(1), 62-64. https://doi.org/10.1016/j.apsoil.2005.12.008

Bhattacharyya, P. N., \& Jha, D. K. (2012). Plant growth-promoting rhizobacteria (PGPR): emergence in agriculture. World Journal of Microbiology and Biotechnology, 28(4), 1327-1350. https://doi.org/10.1007/s11274-011-0979-9

Bric, J. M., Bostock, R. M., \& Silverstone, S. E. (1991). Rapid in situ assay for indoleacetic acid production by bacteria immobilized on a nitrocellulose membrane. Appl. Environ. Microbiol., 57(2), 535-538.

Brown, P. H., Cakmak, I., \& Zhang, Q. (1993). Form and function of zinc plants. In Zinc in soils and plants (pp. 93-106). Springer, Dordrecht.

Cappuccino, J. G., \& Sherman, N. (2005). Microbiology: a laboratory manual (p. 507). San Francisco: Pearson/Benjamin Cummings. Sultenfuss, J. H., \& Doyle, W. J. (1999). Functions of phosphorus in plants. Better Crops, 83(1), 6-7.

Farhat, M. B., Boukhris, I., \& Chouayekh, H. (2015). Mineral phosphate solubilization by Streptomyces sp. CTM396 involves the excretion of gluconic acid and is stimulated by humic acids. FEMS microbiology letters, 362(5), fnv008. https://doi.org/10.1093/femsle/fnv008

Gadd, G. M. (2010). Metals, minerals and microbes: geomicrobiology and bioremediation. Microbiology, 156(3), Https://doi.org/10.1099/mic.0.037143-0

Goswami, D., Pithwa, S., Dhandhukia, P., \& Thakker, J. N. (2014). Delineating Kocuria turfanensis $2 \mathrm{M} 4$ as a credible PGPR: a novel IAA-producing bacteria isolated from saline desert. Journal of Plant Interactions, 9(1), 566-576.

Https://doi.org/10.1080/17429145.2013.871650

Khalid, S., Asghar, H. N., Akhtar, M. J., Aslam, A., \& Zahir, Z. A. (2015). Biofortification of iron in chickpea by plant growth promoting rhizobacteria. Pak J Bot, 47(3), 1191-1194.

King, E. J. (1932). The colorimetric determination of phosphorus. Biochemical Journal, 26(2), 292.

Liu, D., Lian, B., \& Wang, B. (2016). Solubilization of potassium containing minerals by high temperature resistant Streptomyces $\mathrm{sp}$. isolated from $\begin{array}{lll}\text { earthworm's } \quad \text { gut. Acta } & \text { Geochimica, 35(3), }\end{array}$ https://doi.org/10.1007/s11631-016-0106-6

Manulis, S., Shafrir, H., Epstein, E., Lichter, A., \& Barash, I. (1994). Biosynthesis of indole-3-acetic acid via the indole-3-acetamide pathway in Streptomyces spp. Microbiology, 140(5),

https://doi.org/10.1099/13500872-140-5-1045

Medici, L. O., Goncalves, F. V., FONSECA, M. P. S., Gaziola, S. A., Schmidt D., Azevedo, R. A., \& Pimentel, C. (2018). Growth, yield and grain nutritional quality in three Brazilian pearl millets (Pennisetum americanum L.) with African or Indian origins. Anais da Academia Brasileira de Ciências, 90(2), 1749-1758. https://doi.org/10.1590/0001-3765201820170488

Ohki, K. (1976). Effect of zinc nutrition on photosynthesis and carbonic anhydrase activity in cotton. Physiologia Plantarum, 38(4), 300-304.

https://doi.org/10.1016/j.foodchem.2005.04.039

Rajawat, m. V. S., singh, s., \& saxena, a. K. (2014). A new spectrophotometric method for quantification of potassium solubilized by bacterial cultures. Indian journal of experimental biology, 52(3), 261-266.

Rajawat, M. V. S., Singh, S., Tyagi, S. P., \& Saxena, A. K. (2016). A modified plate assay for rapid screening of potassium-solubilizing 
Saif, S., Khan, M. S., Zaidi, A., \& Ahmad, E. (2014). Role of phosphatesolubilizing Actinomycetes in plant growth promotion: current perspective. In Phosphate Solubilizing Microorganisms (pp. 137-156). Springer, Cham. https://doi.org/10.1007/978-3-319-08216-5 6

Saravanan, V. S., Kalaiarasan, P., Madhaiyan, M., \& Thangaraju, M. (2007). Solubilization of insoluble zinc compounds by Gluconacetobacter diazotrophicus and the detrimental action of zinc ion $(\mathrm{Zn} 2+)$ and zinc chelates on root knot nematode Meloidogyne incognita. Letters in applied microbiology, 44(3), 235241. https://doi.org/10.1111/j.1472-765x.2006.02079.x

Sathya, A., Vijayabharathi, R., Srinivas, V., \& Gopalakrishnan, S. (2016). Plant growth-promoting actinobacteria on chickpea seed mineral density: an upcoming complementary tool for sustainable biofortification strategy. 3 Biotech, 6(2), 138. https://doi.org/10.1007/s13205-016-0458-y

Sellstedt, A., \& Richau, K. H. (2013). Aspects of nitrogen-fixing Actinobacteria, in particular free-living and symbiotic Frankia. FEMS Microbiology Letters, 342(2), 179-186. https://doi.org/10.1111/1574-6968.12116

Sharma, S. B., Sayyed, R. Z., Trivedi, M. H., \& Gobi, T. A. (2013). Phosphate solubilizing microbes: sustainable approach for managing phosphorus deficiency in agricultural soils. SpringerPlus, 2(1), 587. https://doi.org/10.1186/2193-18012-587

Sharma, S. K. M. P., Ramesh, A., \& Joshi, O. P. (2011). Characterization of zincsolubilizing Bacillus isolates and their potential to influence zinc assimilation in soybean seeds. Https://doi.org/10.4014/jmb.1106.05063

Uchida, R. (2000). Essential nutrients for plant growth: nutrient functions and deficiency symptoms. Plant nutrient management in Hawaii's soils, 31-55.

Sindhu, S. S., Parmar, P., \& Phour, M. (2014). Nutrient cycling: potassium solubilization by microorganisms and improvement of crop growth In Geomicrobiology and Biogeochemistry (pp. 175-198). Springer, Berlin, Heidelberg. Https://doi.org/10.1007/978-3-642-41837-2

Tamura, K., Dudley, J., Nei, M., \& Kumar, S. (2007). MEGA4: molecular evolutionary genetics analysis (MEGA) software version 4.0. Molecular biology and evolution, 24(8), 1596-1599. https://doi.org/10.1093/molbev/msm092

Teotia, P., Kumar, V., Kumar, M., Prasad, R., \& Sharma, S. (2017). Probiotic Microbiome: Potassium Solubilization and Plant Productivity. In Probiotics in Agroecosystem (pp. 451-467). Springer, Singapore. https://doi.org/10.1007/978981-10-4059-7

Tian, X. P., Long, L. J., Wang, F. Z., Xu, Y., Li, J., Zhang, J., ... \& Li, W. J. (2012). Streptomyces nanhaiensis sp. nov., a marine streptomycete isolated from a deep-sea sediment. International journal of systematic and evolutionary microbiology, 62(4), 864-868. Https://doi.org/10.1099/ijs.0.031591-0

Rajawat, M. V. S., Singh, S., \& Saxena, A. K. (2014). A new spectrophotometric method for quantification of potassium solubilized by bacterial cultures. http://nopr.niscair.res.in/handle/123456789/27350

Weisany, W., Raei, Y., \& Allahverdipoor, K. H. (2013). Role of some of minera nutrients in biological nitrogen fixation. Bulletin of Environment, Pharmacology and Life Sciences, 2(4), 77-84. https://doi.org/10.5702/massspectrometry.a0032 